\begin{tabular}{|c|c|c|}
\hline \multirow{3}{*}{$\begin{array}{l}\text { BENTHAM OPEN } \\
\text { CrossMark }\end{array}$} & $\begin{array}{c}\text { Clinical Practice \& Epidemiology in } \\
\text { Mental Health }\end{array}$ & $\begin{array}{l}\text { Clinical } \\
\text { Practice \& } \\
\text { Epidemiology in } \\
\text { Mental Health }\end{array}$ \\
\hline & Content list available at: www.benthamopen.com/CPEMH/ & gerata \\
\hline & DOI: $10.2174 / 17450179016$ & \\
\hline
\end{tabular}

RESEARCH ARTICLE

\title{
A 13-Weeks Mindfulness Based Pain Management Program Improves Psychological Distress in Patients with Chronic Pain Compared with Waiting List Controls
}

\author{
Tonny Elmose Andersen ${ }^{1, *}$ and Henrik Bjarke Vægter ${ }^{2}$ \\ ${ }^{I}$ Department of Psychology, University of Southern, Campusvej 55, DK-5230 Odense M, Denmark \\ ${ }^{2}$ Clinical Researcher hos Pain Research Group, Pain Center South, University Hospital Odense, Denmark
}

Received: September 21, 2015

Revised: April 06, 2016

Accepted: April 13, 2016

\begin{abstract}
:
Background:

Eradication of pain is seldom an option in chronic pain management. Hence, mindfulness meditation has become popular in pain management.

\section{Objective:}

This pilot study compared the effect of a 13-weeks cognitive behavioural therapy program with integrated mindfulness meditation (CBTm) in patients with chronic non-malignant pain with a control condition. It was hypothesised that the CBTm program would reduce pain intensity and psychological distress compared to the control condition and that level of mindfulness and acceptance both would be associated with the reduction in pain intensity and psychological distress.
\end{abstract}

\section{Methods:}

A case-control design was used and data were collected from a convenience sample of 70 patients with chronic non-malignant pain. Fifty patients were consecutively recruited to the CBTm intervention and 20 patients matched waiting list controls. Assessments of clinical pain and psychological distress were performed in both groups at baseline and after 13 weeks.

Results:

The CBTm program reduced depression, anxiety and pain-catastrophizing compared with the control group. Increased level of mindfulness and acceptance were associated with change in psychological distress with the exception of depression, which was only associated with change in level of mindfulness. Surprisingly, changes in level of mindfulness did not correlate with changes in acceptance.

\section{Conclusions:}

The results indicate that different mechanisms are targeted with cognitive behavioural therapy and mindfulness. The finding that changes in level of mindfulness did not correlate with changes in acceptance may indicate that acceptance is not a strict prerequisite for coping with pain related distress.

Keywords: Chronic Pain, Depression, Mindfulness, Pain Catastrophizing, Psychological Distress.

\footnotetext{
* Address correspondence to this author at the Department of Psychology, University of Southern, Campusvej 55, DK-5230 Odense M, Denmark; Tel: +45 20612003; E-mails: Henrik.Bjarke.Vaegter@rsyd.dk, Henrik.Bjarke.Vaegter@rsyd.dk
} 


\section{BACKGROUND:}

With a prevalence of $20 \%$ and an estimated growth of 7000 new cases per year in Denmark, chronic non-malignant pain comprises a major health problem $[1,2]$. Chronic pain is often associated with psychological distress, which complicates adjustment to chronic pain [3,4], and since eradication of pain is seldom an option, cognitive behavioral therapy has become part of standard treatment helping patients to cope with chronic pain. However, recently a growing number of studies have underlined the importance of fostering acceptance of the chronic condition as an important step in learning to cope with chronic pain. In the context of chronic pain acceptance can be defined as willingness to engage in activity with pain present and to allow the experience of pain without the need to avoid or control it [5].

Mindfulness meditation aims to teach the patient a state of being attentive to and aware of sensations, emotions and thoughts as they take place in the present, and thereby learning patients to accept the unavoidable pain and to disentangle themselves from their distressful thoughts and emotions [6]. Since Kabat-Zinn's introduction of mindfulness based stress reduction for chronic pain in the early eighties [6] various mindfulness-based interventions (MBIs) for chronic pain have been developed. Although the MBIs are not delivered as a homogenous programme, the overall aim of MBIs is to increase mental flexibility by keeping a non-evaluative and non-reactive contact with the present moment [7]. Mental flexibility and acceptance of the chronic pain condition has been associated with less psychological distress and better functioning despite of pain $[8,9]$. Regarding effect sizes, the effect of MBIs in patients with chronic pain is comparable to that of cognitive behavioural therapy programmes with moderate effect sizes reported in relation to pain intensity, anxiety, depression, and physical health [10 - 13]. More specifically, increased level of mindfulness has been positively associated with lower levels of pain related anxiety, depression and disability [5, 14, 15], and lower levels of pain catastrophizing [14]. In addition, pain catastrophizing has been found to mediate the effect of mindfulness on disability and depression. Moreover, the effect of pain catastrophizing on depression was mediated by mindfulness [14]. Overall, the results indicate that level of mindfulness and acceptance of the chronic pain condition are positively correlated with improvement in disability and psychological functioning $[9,15,16]$ and that level of mindfulness is an important mechanism associated with improvement in disability and psychological functioning. For these reasons it has been suggested to integrate both mindfulness and cognitive behaviour therapy into chronic pain management programmes [12]. Although correlations between mindfulness and acceptance and various measures of distress and well-being have been reported [15, 17], few studies have investigated the mechanisms of improved patient functioning in chronic pain [14].

The aims of the present study were to compare the effect of a 13-weeks cognitive behavioural therapy program with integrated mindfulness meditation (CBTm) in patients with chronic non-malignant pain with a control condition and to investigate the association between change in level of mindfulness and acceptance and the change in pain intensity and psychological distress.

It was hypothesised that 1) the CBTm program would reduce pain intensity and psychological distress compared to the control condition, 2) that the CBTm program would increase the level of mindfulness and acceptance of pain, and 3) that the change in level of mindfulness and acceptance both would be associated with the reduction in pain intensity and psychological distress.

\section{METHODS}

\section{Procedure}

In this pilot study, a convenience sample of patients with chronic non-malignant pain was recruited from a multidisciplinary pain centre in the region of Southern Denmark. The pain centre is a specialist, multidisciplinary pain rehabilitation centre that receives referrals from the municipal health care system in Denmark. The team of specialists includes anaesthesiologists, nurses, physiotherapists, social workers, as well as clinical psychologists. The majority of pain conditions are widespread or musculoskeletal in origin although patients with headache and abdominal pain, which may not be musculoskeletal in origin, are also referred for treatment [18]. Ninety-six invitation letters were consecutively mailed to participants prior to commencing the 13 weeks CBTm program. Patients in the control group were recruited from the pain center's waiting list. Eighty invitation letters were consecutively mailed to patients at the waiting list. Contact information for one of the investigators was provided to participants for study-related questions. Assessments of pain intensity and psychological distress were performed in both groups at baseline and after 13 weeks. Patients from both groups of the study continued to receive their usual medical care throughout the study period.

The research protocol was approved by the review board of the University of Southern Denmark. Furthermore, all 
participants in the study volunteered freely and written consent to participate in the research project was given at admission to the pain centre.

\section{Outcome Measures}

Questionnaires were given at baseline to assess patient characteristics. These included gender, age, and previous experience with relaxation or mindfulness. The primary outcome measures in this study were as follows:

\section{Pain Intensity}

Pain intensity was assessed for peak pain intensity, lowest pain intensity, and average pain intensity over the past week as well as current pain. Each scale measured pain intensity on a 0-10 numerical rating scale (NRS) with 0 defined as no pain and 10 as the worst imaginable pain. For data analysis, a total pain intensity was calculated as the average of the four NRS scales. Internal consistency measured by Cronbach's alpha was good (T1-T2, $\alpha=.81-.90)$.

\section{Depression and Anxiety}

The Hospital Anxiety and Depression Scale (HADS; [19]) was used to assess the level of depressive symptoms. The scale consists of 14 items, seven relating to anxiety (HADS-A) and seven to depression (HADS-D), with responses ranging from 0 (no symptoms) to 3 (maximum impairment). A cut-off score of $\geq 8$ on each subscale was used in order to include all possible cases of depression and anxiety, as suggested by [19]. Internal consistency measured by Cronbach's alpha was good (T1-T2, $\alpha=.88-.89)$.

\section{Pain Catastrophizing}

The Pain Catastrophizing Scale (PCS; [20]) was used to measure catastrophic thinking related to pain. The PCS instructions ask participants to reflect on past painful experiences, and to indicate the degree to which they experienced each of 13 thoughts or feelings when experiencing pain, on a five-point Likert scale with $(0=$ not at all, $4=$ all the time). Scale sum score was calculated from all items, with a high score indicating a high level of pain catastrophizing. Internal consistency measured by Cronbach's alpha was good (T1-T2, $\alpha=.90-.94)$.

\section{Level of Mindfulness}

Level of mindfulness was measured by the 15 items Mindfulness Attention and Awareness Scale (MAAS; [17]). A total score of mindfulness was comprised by the 15 items assessing the subjective experience of present moment attention and awareness in different situations (for example; "I find it difficult to stay focused on what's happening in the present"). Items were rated on a 6 -point Likert scale ( $1=$ almost always to $6=$ almost newer), with higher scores indicating a greater degree of mindfulness (mindful behavior). The internal consistency of the MAAS as measured by Cronbach's alpha, was good (T1-T2, $\alpha=.89-.91)$.

\section{Acceptance}

The Chronic Pain Acceptance Questionnaire (CPAQ; [21]) was used to measure acceptance of chronic pain. The scale is a 20-item measure of acceptance of chronic pain that yields a total score and two subscale scores for pain willingness and activity engagement. The scale has been widely used in studies of chronic pain and has good psychometric properties [21]. The internal consistency of the CPAQ as measured by Cronbach's alpha, was good (T1$\mathrm{T} 2, \alpha=.86-.88)$.

\section{The CBTm Program}

For 13 consecutive weeks, the treatment group engaged in the CBTm program with classroom learning once per week for 2.5 hours. Homework and mindfulness exercises were assigned in between sessions. Written materials and audio CDs were provided to support home practice. The program was led by two professionally mindfulness based cognitive therapy (MBCT) trained psychologists and long term meditators and conducted in groups of 8-10 patients. The main goal of the program was not eradication of pain symptoms, but management of the pain condition and reduction of psychological distress. The program was delivered as a standard cognitive behavioural therapy program for chronic pain [22] integrating elements of mindfulness training as described in the MBCT program [23]. The program consisted of the following topics and exercises: education in pain physiology and theory, pain coping strategies, mindfulness exercises, activity-rest scheduling, assertive communication, acceptance strategies and restructuring of 
maladaptive thoughts.

\section{Statistics}

Prior to data analysis, the data were screened for errors and missing values. The percentage of missing values was small $(<5 \%)$. The Expectation Maximization algorithm was used to impute missing data [24]. Results are presented as mean and standard deviation (SD) in the text and mean and standard error of the mean (SEM) in figures. None of the measured variables deviated from normality (Kolmogorov-Smirnoff test: $P>0.05$ ) and parametric statistics were used for analysis. Baseline characteristics for all included patients were analysed with chi squares test for dichotomous data and with independent sample t-test for continuous data. Moreover, a dropout analysis comparing baseline characteristics for patients who completed the study and patients who dropped out was performed. Two-way repeated measures analysis of variances (ANOVAs) were used for analysis of the outcome measures for the patients who completed the study with the factor time (baseline and follow up) as repeated measure and group (treatment and control) as between factor. In case of significant factors or interactions, the Newman-Keuls (NK) post-hoc test was used incorporating correction for the multiple comparisons. Percentages of patients in the two groups with scores $\geq 8$ on HADS (depression and anxiety) at follow up were analysed with chi squares test.

$P$ values less than 0.05 in the ANOVAs were considered significant. Effect sizes of the difference in outcome measures between groups were calculated based on Hedges' g, due to dissimilar group sizes. Finally, Pearson correlations were used to determine how changes in pain intensity and psychological distress were associated with changes in mindfulness attention and awareness and acceptance of chronic pain. To address the multiple correlational analyses, we applied a more conservative criterion $(p \leq 0.01)$ to all correlational analyses as a means of reducing the likelihood of type I errors without overly inflating the risk of type II errors.

\section{RESULTS}

\section{Baseline Characteristics}

Fig. (1) illustrates the patient flow in this study. Of the 96 patients who were eligible to participate in the treatment group, 80 patients completed baseline questionnaires and 50 patients completed questionnaires after 13 weeks. Of the 80 patients who were eligible to participate in the control group, 45 patients completed baseline questionnaires and 20 patients completed questionnaires after 13 weeks.
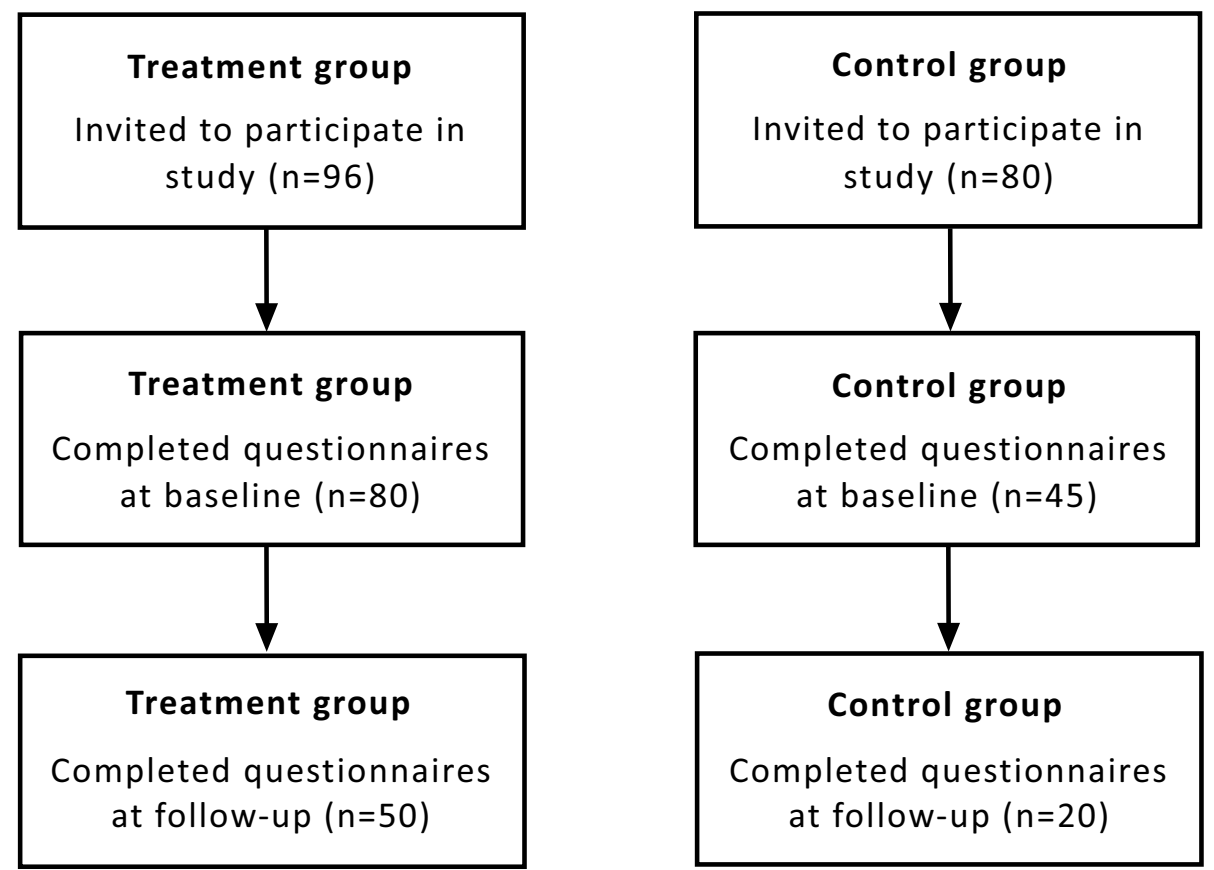

Fig. (1). Flow diagram of the patients in the two groups participating in this study. 
Table 1 compares baseline characteristics in the treatment and control group at baseline. A significantly larger percentage of the patients in the treatment group had previous experience with relaxation compared with patients in the control group. There was no significant difference in demographics, pain intensity or psychological variables between the groups at baseline.

Table 1. Patient characteristics in the control and treatment group at baseline.

\begin{tabular}{|c|c|c|c|}
\hline Variable & $\begin{array}{c}\text { Control group } \\
(n=45)\end{array}$ & $\begin{array}{c}\text { Treatment group } \\
(\mathbf{n}=\mathbf{8 0})\end{array}$ & $\begin{array}{c}P \\
\text { value }\end{array}$ \\
\hline Age (years) & $42.9 \pm 11.0$ & $44.8 \pm 11.8$ & $0.38^{\mathrm{a}}$ \\
\hline $\operatorname{Sex}(\mathrm{F} / \mathrm{M})$ & $35 / 10$ & $63 / 17$ & $0.90^{\mathrm{b}}$ \\
\hline Previous experience with relaxation & $10(22.2 \%)$ & $31(40.3 \%)$ & $0.04^{\mathrm{b}}$ \\
\hline Previous experience with mindfulness & $7(15.6 \%)$ & $20(26.3 \%)$ & $0.17^{\mathrm{b}}$ \\
\hline Pain intensity (NRS: $0-10)$ & $6.4 \pm 1.5$ & $6.0 \pm 1.4$ & $0.18^{\mathrm{a}}$ \\
\hline Depression (HAD: 0-21) & $7.8 \pm 4.5$ & $7.4 \pm 4.2$ & $0.60^{\mathrm{a}}$ \\
\hline Subjects with depression (HAD $\geq 8$ ) & $22(48.9 \%)$ & $40(50 \%)$ & $0.91^{\mathrm{b}}$ \\
\hline Anxiety (HAD: 0-21) & $9.6 \pm 4.9$ & $8.4 \pm 3.6$ & $0.11^{\mathrm{a}}$ \\
\hline Subjects with anxiety (HAD $\geq 8)$ & $28(62.2 \%)$ & $47(58.8 \%)$ & $0.70^{\mathrm{b}}$ \\
\hline Pain Catastrophizing (PCS: 0-52) & $30.5 \pm 9.4$ & $27.0 \pm 10.1$ & $0.06^{\mathrm{a}}$ \\
\hline Level of mindfulness (MAAS: $15-90$ ) & $56.7 \pm 16.5$ & $55.1 \pm 13.4$ & $0.56^{\mathrm{a}}$ \\
\hline Pain Acceptance (CPAQ: 0-120) & $49.4 \pm 16.0$ & $53.1 \pm 17.1$ & $0.24^{\mathrm{a}}$ \\
\hline
\end{tabular}

${ }^{\mathrm{a}}$ Independent T-Test

${ }^{\mathrm{b}}$ Chi Square Test

'NRS': Numerical Rating Scale, 'HAD': Hospital Anxiety and Depression Scale, 'PCS': Pain Catastrophizing Scale, 'MAAS': Mindfulness Attention and Awareness Scale, 'CPAQ': Chronic Pain

\section{Drop-out Analysis}

Twenty-five patients from the control group did not complete questionnaires after 13 weeks. There was no significant difference in pain intensity or psychological variables between patients who dropped out and patients who completed the study $(-1.04<\mathrm{t}(43)<1.67, P>0.1)$. Patients in the control group who completed the study was older compared with dropouts; however, the difference did not reach significance $(\mathrm{t}(43)=1.97, P=0.06)$.

Thirty patients from the treatment group did not complete questionnaires after 13 weeks. There was no significant difference in demographics, pain intensity or psychological variables between patients who dropped out and patients who completed the study $(-1.70<\mathrm{t}(78)<1.11, P>0.09)$.

\section{Follow-up}

The baseline and follow-up scores for patients in the treatment and control groups who completed the study are presented in Table 2.

Table 2. Mean \pm SD $(n=70)$ clinical pain scores and psychological variables before and after 13 weeks in the treatment and control groups. Significant differences between baseline and follow-up $(*, P<0.05)$, and significant differences between groups $(\dagger, P<0.05)$.

\begin{tabular}{|c|c|c|c|c|c|}
\hline \multirow{2}{*}{ Variable } & \multicolumn{2}{|c|}{ Treatment group $(\mathrm{N}=50)$} & \multicolumn{2}{|c|}{ Control group $(\mathrm{N}=20)$} & \multirow{2}{*}{ Effect size } \\
\hline & Baseline & Follow-up & Baseline & Follow-up & \\
\hline Peak intensity (NRS: 0-10) & $5.9 \pm 1.3$ & $5.9 \pm 1.9$ & $6.3 \pm 1.8$ & $6.6 \pm 2.0$ & 0.00 \\
\hline Depression (HAD: 0-21) & $7.7 \pm 3.8$ & $6.0 \pm 3.4 * \dagger$ & $7.5 \pm 4.6$ & $8.1 \pm 5.2$ & 0.56 \\
\hline Anxiety (HAD: 0-21) & $8.7 \pm 3.6$ & $7.0 \pm 3.3^{*}$ & $10.3 \pm 4.5$ & $9.6 \pm 5.1 *$ & 0.36 \\
\hline Pain Catastrophizing (PCS: 0-52) & $28.0 \pm 8.6$ & $21.0 \pm 8.9 * \dagger$ & $33.1 \pm 9.4$ & $31.8 \pm 10.7$ & 0.53 \\
\hline Level of mindfulness (MAAS: 15-90) & $54.0 \pm 12.4$ & $57.9 \pm 10.8$ & $57.0 \pm 14.6$ & $53.4 \pm 15.7$ & 0.54 \\
\hline Pain Acceptance (CPAQ: 0-120) & $52.6 \pm 17.2$ & $60.7 \pm 15.0 *$ & $46.6 \pm 17.3$ & $49.4 \pm 23.3 *$ & 0.51 \\
\hline
\end{tabular}

\section{Pain Intensity}

There was no significant main effects or interactions in the ANOVA (Treatment group: from $5.9 \pm 1.3$ to $5.9 \pm 1.9$; Control group: from $6.3 \pm 1.8$ to $6.6 \pm 2.0 ; \mathrm{F}(1,68)<0.61, P>0.43)$ indicating that CBTm did not reduce pain intensity compared with the waiting list.

\section{Depression and Anxiety}

The treatment group had a reduction in the score on the depression subscale from baseline to follow-up, whereas the control group had an increase (Treatment group: from 7.7 \pm 3.8 to $6.0 \pm 3.4$; Control group: from 7.5 \pm 4.6 to 8.1 \pm 5.2 ; Effect size: 0.56). A significant interaction between group and time was found in the $\operatorname{ANOVA}(\mathrm{F}(1,68)=9.82, P<$ 0.003; Fig. 2), with post hoc test showing a significant decrease in the depression score at follow-up in the treatment 
group compared with baseline and the control group (NK: $P<0.004)$. Furthermore, significantly fewer percent of the patients $(30.0 \%)$ in the treatment group had a total score of $\geq 8$ on the depression subscale compared with patients in the control group (65.0\%; Chi Square, $P<0.007)$.

21

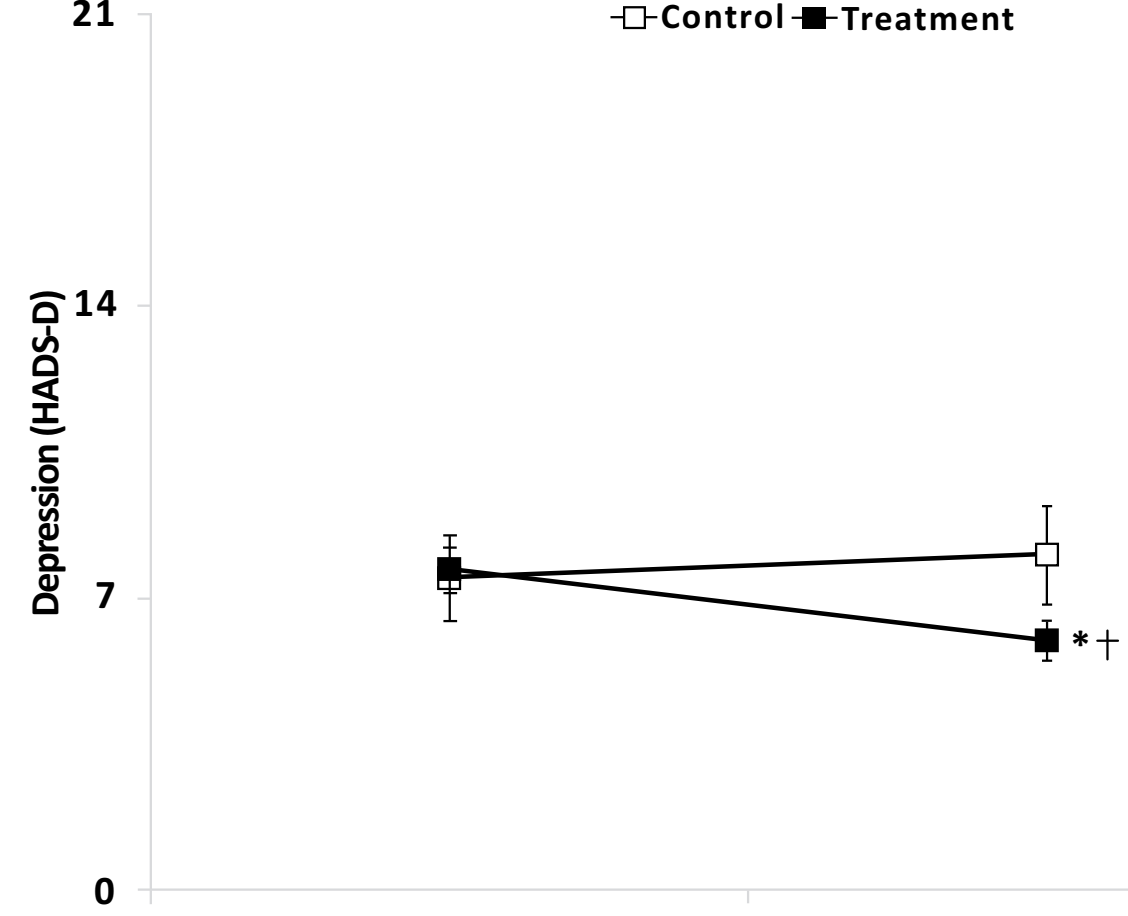

Baseline
Follow-up

Fig. (2). Mean $( \pm$ SEM) depression score (HADS-D) in the treatment group (filled squares, $n=50)$ and the control group (open squares, $\mathrm{n}=20)$ at baseline and follow-up. Significantly different compared with baseline $(*, \mathrm{NK}: P<0.05)$ and significantly different compared with control group $(\dagger, \mathrm{NK}: P<0.05)$.

Both groups had a reduction in the score on the anxiety subscale from baseline to follow-up (Treatment group: from $8.7 \pm 3.6$ to $7.0 \pm 3.3$; Control group: from $10.3 \pm 4.5$ to $9.6 \pm 5.1$; Effect size: 0.36 ) and the ANOVA demonstrated a significant main effect of time $(\mathrm{F}(1,68)=8.10, P<0.006)$, with post hoc test showing a significant decrease in the anxiety score at follow up in both groups compared with baseline (NK: $P<0.003)$. However, significantly fewer percent of the patients $(36.0 \%)$ in the treatment group had a total score of $\geq 8$ on the anxiety subscale in the HADS compared with patients in the control group $(65.0 \%$; Chi Square, $P<0.03)$.

\section{Pain Catastrophizing}

Both groups had a reduction in pain catastrophizing from baseline to follow-up (Treatment group: from $28.0 \pm 8.6$ to $21.0 \pm 8.9$; Control group: from $33.1 \pm 9.4$ to $31.8 \pm 10.7$; Effect size: 0.53 ). A significant interaction was found in the ANOVA between group and time $(\mathrm{F}(1,68)=4.86, P<0.04$; Fig. 3), with post hoc test showing a significant decrease in the treatment group at follow-up compared with baseline (NK: $P<0.001)$. The treatment group had a significant lower score at baseline and follow-up compared with the control group (NK: $P<0.02)$. 


\section{$-\square$-Control $\rightarrow$-Mindfulness}

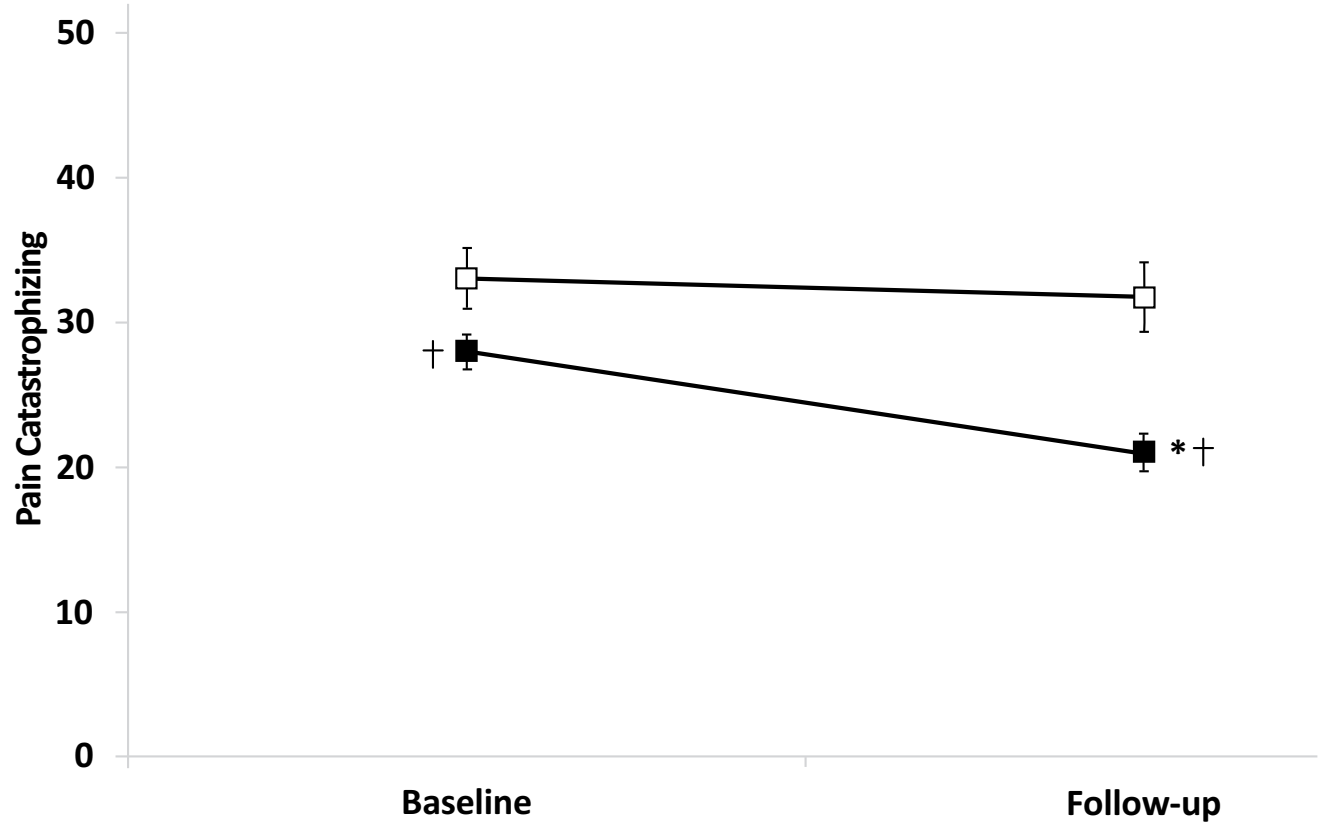

Fig. (3). Mean $( \pm S E M)$ score on the Pain Catastrophizing Scale $(P C S)$ in the treatment group (filled squares, $n=50)$ and the control group (open squares, $\mathrm{n}=20)$ at baseline and follow-up. Significantly different compared with baseline $(*, \mathrm{NK}: P<0.05)$ and significantly different compared with control group $(\dagger, \mathrm{NK}: P<0.05)$.

\section{Acceptance}

Both groups had an increase in the total score of the Chronic Pain Acceptance Questionnaire from baseline to follow-up (Treatment group: from $52.6 \pm 17.2$ to $60.7 \pm 15.0$; Control group: from $46.6 \pm 17.3$ to $49.4 \pm 23.3$; Effect size: 0.51 ) as well as in the willingness to be active despite pain subscale (Treatment group: from $20.6 \pm 9.4$ to $25.6 \pm$ 8.3; Control group: from $17.0 \pm 7.9$ to $20.4 \pm 10.7$; Effect size: 0.30). A significant main effect of time was found in the ANOVA of the total score of CPAQ as well as in the willingness to be active despite pain subscale $(\mathrm{F}(1,68)=11.64, P$ $<0.002$ and $\mathrm{F}(1,68)=18.43, P<0.001$, respectively) with post hoc test showing a significant increase in the scores at follow up in both groups compared with baseline (NK: $P<0.001$ ).

The treatment group had an increase in the activity engagement subscale from baseline to follow-up (from $32.2 \pm$ 10.9 to $35.1 \pm 10.7$ ), whereas the control group had a decrease (from $29.6 \pm 11.3$ to $29.0 \pm 15.1$ ). The ANOVA approached a significant interaction between time and group $(\mathrm{F}(1,68)<3.36, P=0.07)$.

\section{Mindfulness Attention and Awareness}

The treatment group had an increase in the score on the MAAS from baseline to follow-up, whereas the control group had a decrease (Treatment group: from $54.0 \pm 12.4$ to $57.9 \pm 10.8$; Control group: from $57.0 \pm 14.6$ to $53.4 \pm$ 15.7; Effect size: 0.54$)$. A significant interaction between group and time was found in the ANOVA $(\mathrm{F}(1,68)=5.90, P$ $<0.02$ ), however, post hoc test failed to reach significance between baseline or follow-up or between the groups at any time point (NK: $P>0.08)$.

\section{Associations between Changes in MAAS/CPAQ and Changes in Pain Intensity and Psychological Distress}

Significant correlations were found between change in the MAAS score from baseline to follow-up and changes in psychological distress indicating that increased level of mindfulness had a positive effect on changes in psychological distress following treatment. The correlations are as follows: Depression score $(\mathrm{r}(68)=0.31, P=0.01)$, pain catastrophizing scale $(\mathrm{r}(68)=0.45, P<0.001)$, anxiety score $(\mathrm{r}(68)=0.38, P=0.001)$. Significant correlations were also found between change in the CPAQ score from baseline to follow-up and change in the pain catastrophizing scale $(\mathrm{r}(68)=0.51, P<0.001)$, and anxiety score $(\mathrm{r}(68)=0.33, P=0.005)$. Correlations between pain intensity and MAAS 
$(\mathrm{r}(68)=0.25, P=0.04)$, and pain intensity and CPAQ (r(68) $=0.27, P=0.02)$ approached significance.

There was no significant correlation between change in the CPAQ score from baseline to follow-up and change in the MAAS score $(\mathrm{r}(68)=0.01, P=0.91)$.

\section{DISCUSSION}

This pilot study investigated the effect of a 13 weeks cognitive behavioural therapy program with integrated mindfulness meditation (CBTm). As hypothesized, the program reduced psychological distress (pain-catastrophizing, depression, and anxiety) compared to the control group. Although, the CBTm group increased in level of mindfulness and acceptance and the controls decreased, the difference was not significant. Also, as hypothesized, the increased level of mindfulness and acceptance were negatively associated with all measures of psychological distress with the exception of depression, which was only associated with change in level of mindfulness.

The findings of reduced psychological distress are in accordance with previous studies reporting moderate effect sizes of both MBI and cognitive behavioural therapy [10,13]. Surprisingly, changes in level of mindfulness did not correlate with changes in acceptance, although both scores correlated with changes in psychological distress. This finding may indicate that different mechanisms are targeted with cognitive behavioural therapy techniques and mindfulness. In specific, the finding that only change in level of mindfulness was associated with change in depression could indicate that one of the mechanisms of mindfulness is the ability to uncouple the emotional components of pain, and thereby reduce symptoms of distress. The result is in accordance with the theoretical rationale for mindfulness emphasizing that mental flexibility is important in coping with distress [25]. Moreover, the finding that changes in level of mindfulness did not correlate with changes in acceptance may indicate that acceptance is not a strict prerequisite for coping with pain related distress. For this reason the integration of mindfulness meditation in cognitive behavioural therapy programmes may have some advantages above cognitive behavioural therapy alone. However, this still needs to be tested in a randomized controlled trial in the context of chronic pain rehabilitation. Although, more follow-up studies are needed, evidence indicates that the effect of MBIs on pain related distress may be maintained up to 3-years posttreatment [26]. In comparison, the long-term effects of cognitive behavioural therapy for chronic pain are quite modest [13]. Hence, it may be beneficial integrating more MBI techniques into cognitive behavioural therapy programmes for chronic pain.

\section{Limitations}

Limitations regarding the interpretation of the results from this study should be taken into consideration. First of all, this study was intended as a pilot study and is as such limited by the small sample size. Limitations include lack of statistical power as well as risk of false positive results and the results should be interpreted with care. Larger studies should confirm the findings of this study. Also, the lack of randomization and the short follow-up time are major limitations. Secondly, the high level of drop-outs, especially in the control group is a limitation. Moreover, the CBTm group had more prior experience with relaxation, compared to the control group, which may be a confounder. In spite of these limitations, this pilot study adds important knowledge about possible mechanisms of mindfulness and acceptance in relation to coping with chronic pain. In particular, the associations between increase in both mindfulness and acceptance and positive change in psychological distress and pain is encouraging.

\section{CONCLUSION}

A 13-weeks CBTm program reduced depression and pain catastrophizing in patients with chronic non-malignant pain compared with the control group. The reduction in catastrophizing and anxiety were negatively associated with the increased level of mindfulness and acceptance and the reduction in depression was negatively associated with the increased level of mindfulness. For these reasons, the integration of mindfulness into cognitive behavioural therapy programmes for chronic pain seems promising.

\section{CONFLICT OF INTEREST}

The authors confirm that this article content has no conflict of interest.

\section{ACKNOWLEDGEMENTS}

We thank the clinical psychologists and the secretary at the Pain Centre for their assistance in data collection. 


\section{REFERENCES}

[1] Sjøgren P, Ekholm O, Peuckmann V, Grønbaek M. Epidemiology of chronic pain in Denmark: an update. Eur J Pain 2009; 13(3): 287-92. [http://dx.doi.org/10.1016/j.ejpain.2008.04.007] [PMID: 18547844]

[2] Harker J, Reid KJ, Bekkering GE, et al. Epidemiology of chronic pain in Denmark and Sweden. Pain Res Treat 2012; 2012 : 371248. [http://dx.doi.org/10.1155/2012/371248]

[3] Bair MJ, Robinson RL, Katon W, Kroenke K. Depression and pain comorbidity: a literature review. Arch Intern Med 2003; $163(20)$ : $2433-45$. [http://dx.doi.org/10.1001/archinte.163.20.2433] [PMID: 14609780]

[4] Tunks ER, Crook J, Weir R. Epidemiology of chronic pain with psychological comorbidity: prevalence, risk, course, and prognosis. Can J Psychiatry 2008; 53(4): 224-34. [PMID: 18478825]

[5] McCracken LM, Vowles KE, Gauntlett-Gilbert J. A prospective investigation of acceptance and control-oriented coping with chronic pain. J Behav Med 2007; 30(4): 339-49. [http://dx.doi.org/10.1007/s10865-007-9104-9] [PMID: 17447131]

[6] Kabat-Zinn J. An outpatient program in behavioral medicine for chronic pain patients based on the practice of mindfulness meditation: theoretical considerations and preliminary results. Gen Hosp Psychiatry 1982; 4(1): 33-47. [http://dx.doi.org/10.1016/0163-8343(82)90026-3] [PMID: 7042457]

[7] Reiner K, Tibi L, Lipsitz JD. Do mindfulness-based interventions reduce pain intensity? A critical review of the literature. Pain Med 2013; 14(2): 230-42 [http://dx.doi.org/10.1111/pme.12006] [PMID: 23240921]

[8] McCracken LM, Keogh E. Acceptance, mindfulness, and values-based action may counteract fear and avoidance of emotions in chronic pain: an analysis of anxiety sensitivity. J Pain 2009; 10(4): 408-15. [http://dx.doi.org/10.1016/j.jpain.2008.09.015] [PMID: 19327643]

[9] Wicksell RK, Ahlqvist J, Bring A, Melin L, Olsson GL. Can exposure and acceptance strategies improve functioning and life satisfaction in people with chronic pain and whiplash-associated disorders (WAD)? A randomized controlled trial. Cogn Behav Ther 2008; 37(3): 169-82. [http://dx.doi.org/10.1080/16506070802078970] [PMID: 18608312]

[10] Chiesa A, Serretti A. Mindfulness-based interventions for chronic pain: a systematic review of the evidence. J Altern Complement Med 2011; 17(1): 83-93. [http://dx.doi.org/10.1089/acm.2009.0546] [PMID: 21265650]

[11] Grossman P, Niemann L, Schmidt S, Walach H. Mindfulness-based stress reduction and health benefits. A meta-analysis. J Psychosom Res 2004; 57(1): 35-43.

[http://dx.doi.org/10.1016/S0022-3999(03)00573-7] [PMID: 15256293]

[12] Veehof MM, Oskam MJ, Schreurs KM, Bohlmeijer ET. Acceptance-based interventions for the treatment of chronic pain: a systematic review and meta-analysis. Pain 2011; 152(3): 533-42. [http://dx.doi.org/10.1016/j.pain.2010.11.002] [PMID: 21251756]

[13] Williams AC, Eccleston C, Morley S. Psychological therapies for the management of chronic pain (excluding headache) in adults. Cochrane Database Syst Rev 2012; 11: CD007407. [http://dx.doi.org/10.1002/14651858.CD007407.pub3] [PMID: 23152245]

[14] Cassidy EL, Atherton RJ, Robertson N, Walsh DA, Gillett R. Mindfulness, functioning and catastrophizing after multidisciplinary pain management for chronic low back pain. Pain 2012; 153(3): 644-50. [http://dx.doi.org/10.1016/j.pain.2011.11.027] [PMID: 22240149]

[15] McCracken LM, Thompson M. Components of mindfulness in patients with chronic pain. J PsychopatholBehav 2009; $31(2)$ : 75-82. [http://dx.doi.org/10.1007/s10862-008-9099-8]

[16] McCracken LM, Gutiérrez-Martínez O, Smyth C. "Decentering" reflects psychological flexibility in people with chronic pain and correlates with their quality of functioning. Health Psychol 2013; 32(7): 820-3. [http://dx.doi.org/10.1037/a0028093] [PMID: 22545976]

[17] Brown KW, Ryan RM. The benefits of being present: mindfulness and its role in psychological well-being. J Pers Soc Psychol 2003; 84(4): $822-48$. [http://dx.doi.org/10.1037/0022-3514.84.4.822] [PMID: 12703651]

[18] Vaegter HB, Graven-Nielsen T. Pain modulatory phenotypes differentiate subgroups with different clinical and experimental pain sensitivity. Pain 2016. [Epub ahead of print]. [PMID: 26963852]

[19] Zigmond AS, Snaith RP. The hospital anxiety and depression scale. Acta Psychiatr Scand 1983; 67(6): 361-70. [http://dx.doi.org/10.1111/j.1600-0447.1983.tb09716.x] [PMID: 6880820]

[20] Sullivan MJ, Bishop SR, Pivik J. The pain catastrophizing scale: development and validation. Psychol Assess 1995; 7: 524-32. [http://dx.doi.org/10.1037/1040-3590.7.4.524]

[21] McCracken LM, Vowles KE, Eccleston C. Acceptance of chronic pain: component analysis and a revised assessment method. Pain 2004; 
107(1-2): 159-66.

[http://dx.doi.org/10.1016/j.pain.2003.10.012] [PMID: 14715402]

[22] Turk DC, Gatchel RJ. Psychological approaches to pain management: a practitioner's handbook. $2^{\text {nd }}$ ed. New York: Guilford Press 2002.

[23] Segal ZV, Williams JM, Teasdale JD. Mindfulness-based cognitive therapy for depression: a new approach to preventing relapse. New York: Guilford Press 2001.

[24] Bunting B, Adamson G, Mulhall P. A montecarlo examination of an MTMM model with planned incomplete data structures. Struct Equ Modeling 2002; 9: 369-89.

[http://dx.doi.org/10.1207/S15328007SEM0903_4]

[25] Brown KW, Ryan RM, Creswell JD. Mindfulness: Theoretical foundations and evidence for its salutary effects. Psychol Inq 2007 ; $18: 211-37$. [http://dx.doi.org/10.1080/10478400701598298]

[26] Grossman P, Tiefenthaler-Gilmer U, Raysz A, Kesper U. Mindfulness training as an intervention for fibromyalgia: evidence of postintervention and 3-year follow-up benefits in well-being. Psychother Psychosom 2007; 76(4): 226-33. [http://dx.doi.org/10.1159/000101501] [PMID: 17570961]

(C) Andersen and Vægter; Licensee Bentham Open.

This is an open access articles licensed under the terms of the Creative Commons Attribution-Non-Commercial 4.0 International Public License (CC BY-NC 4.0) (https://creativecommons.org/licenses/by-nc/4.0/legalcode), which permits unrestricted, non-commercial use, distribution and reproduction in any medium, provided that the work is properly cited. 